\title{
Disabled University Students: An Exploratory Study of a Support Program in a Spanish University
}

\author{
Ángel Iglesias \\ University Rey Juan Carlos
}

Spanish universities are mostly designed to accommodate normal students who do not have any kind of disability. This is evident not only in the physical structures, but also in the curricular designs, in the methodologies used and in the absence of training for lectures and administrative staff. In this context, the purpose of this paper is to present the objectives and measures of the student support service policy of a Spanish university. To this end, we will firstly describe and analyze the objectives and actions within the program, and then carry out a first qualitative evaluation and assessment based on semi-structured interviews with disabled students who are the beneficiaries of the program. The initial results show low satisfaction on the part of the beneficiary students and a perception of the need to take into account the educational requirements of students with disabilities.

Keywords: Spain, university students, disabled students, physical disorders, special education

\section{INTRODUCTION}

The importance of disabled students at universities has become an important issue of debate for inclusive higher education (Riddel, 2005; Fuller, Georgeson, Healey, Hurst, Kelly and Riddell, 2009; Harvey, 2018). Over the last two decades' research has grown as has the literature evaluating its outcomes (Taylor, 2004; Konur, 2006; Seale, 2006; Brandt, 2011; Beauchamp-Pryor, 2013; Riddell and Weedon, 2014). Within this context, the aim of the present study is, first, to describe the program implemented by a Spanish University concerning the integration of its handicapped students and, second, to make a preliminary exploratory evaluation of this policy.

This is an exploratory study and, therefore, is mostly descriptive. It has been carried out through a qualitative research approach including the analysis of internal documents and semi-structured interviews with beneficiary students of the program and some outcomes have been identified. Other key stakeholders involved in the implementation of the policy were not available. The paper concludes by suggesting some additional practices to ensure that handicapped students needs are seriously considered.

The importance of removing barriers for handicapped university students has become a central aspect of the European Commission's Strategy, which focuses on removing barriers. Spanish Universities are designed for not handicapped students, but over the last decade they have formulated different programs forced by the increase numbers of students with a varied range of disabilities. These programs build on the assumption that in order to achieve high levels in educational services they need to focus on removing several barriers that affect handicapped students. In this context, the Spanish university system fully 
understands, at least in theory, the importance of inclusive education, which contributes to the construction of a cohesive society that respects the principle of equal opportunities and non- discrimination.

\section{HANDICAPPED STUDENTS IN SPANISH UNIVERSITIES}

Within the Spanish university system, students with disabilities represent $1.7 \%$ of the total number of students. There has been an increase of university students with disabilities that continues in global terms, as they go from represent $1.3 \%$ to $1.7 \%$. Although in absolute terms this figure is low, this increase is observed to a greater extent in universities financed by public funds.

Obviously, the Spanish Constitution and several ordinary laws recognize that any person with a disability has the right to access to university education. Accordingly, the Conference of Rectors of Spanish Universities (CRUE) issued the document "Social Commitment and Volunteering" and signed a Framework Agreement between the CRUE and the Spanish Committee of Representatives of People with Disabilities, on 20 November 2003.

Additionally, many Regional Governments (Autonomous Communities) have approved legislation and programs for people with disabilities, expressing the will of the regional governments concerning basic instruments of inclusion policies, non-discrimination and positive action to ensure effective equality of opportunity.

With this in mind, most universities have specific regulations governing the right to equal opportunities for students with disabilities. In most cases, these regulations are set out in the university's statutes and in its several internal regulations including, Strategic Plans for Social Responsibility and Codes of Ethics, among others.

\section{CASE STUDY: MAIN FEATURES OF THE SUPPORT PROGRAM FOR HANDICAPPED STUDENTS AT THE UNIVERSITY REY JUAN CARLOS (URJC)}

\section{Background Information on the Program}

The University recognizes that quality teaching is one of its fundamental objectives that become more important when considering disabled students, since they require additional guarantees to varying degrees, in order to live with full rights or participate on an equal footing with the rest of the citizens.

Taking into account the general rules on disability, Article 3 of the University's statutes include among their aims to "ensure the social projection of its activities [...] with particular attention to the continuing education of [...] the disabled. Article 141(d) and (k) also provide for the right to students to have adequate facilities to allow their normal development with special attention to persons with disabilities, as well as the right not to be discriminated on the basis of personal or social circumstances, including disability, in the access to the University. Finally, Article 145.2 states that the University shall guarantee equal access for students to the teaching and services provided by it, with special attention to guaranteeing the right to education for students with physical and sensory disabilities or both.

\section{Inclusion of Disability in Curricula}

The URJC makes provisions so that those responsible for education in the final year of high school, as well as parents or guardians who contact the University for prospective students, will be informed about the support that the University can give them as well as to collect information on their needs in advance to be able to manage the technical and human resources, and to assist them in the task of choosing a suitable career for their functional possibilities. In the university entrance exams, technical aids are made available for those who require them. Also, appropiate training is provided for the staff who may have a direct relationship with the students in the entrance and registration processes. Furthermore, the URJC reserves $5 \%$ of the places available in all his degrees, including postgraduate and doctoral programs.

Concerning curricular adaptations, the URJC establishes procedures that enable the different Departments proceed with the curricular adaptations that are necessary, in order to adapt the process of teaching-learning in accordance to the individual possibilities of each student with a disability and 
according to the specific needs of each student, provided that these do not affect the basic content of the knowledge nor cause changes in academic content, nor affect the requirement of mastery of skills and abilities and nor discrimination against any another student. During the continuous evaluation process, alternative assessment modalities are applied for students with specific disabilities and students with special educational needs associated with any disability will have the possibility of taking the exam orally.

Participation of students with disabilities in national and international mobility programs such as Erasmus is also fostered, and labor orientation is also offered to favor the insertion of students and graduates with disabilities in the labor market.

\section{Support Services Organization and Budget}

The Unit for disability services is located at the high level within the Vice-Rector's Office of Social Policy that produces and keeps an updated census of students with disability. In addition, in Faculties where students with disabilities are enrolled, the Dean appoints at one person responsible for all the interactions with handicapped students.

The Unit prepares information and guidance materials and promotes collaboration agreements with institutions that allow the development of joint actions. It also promotes actions to make the entire university community aware of the situation of people with disability and ensures that students with disabilities have access to information within the University. The Unit coordinates actions with Secondary Education and Baccalaureate institutions in the educational orientation phase and in planning adaptations in university access tests, university open days and the like. It also promotes actions during the educational process: tutoring and monitoring programs, psycho-educational support and academic reinforcement in order to optimize academic results and reduce drop-out rates, national and international mobility programs, personal assistance and job adaptations. The tutoring and monitoring programs consist of assigning an academic tutor that provides proximity to the student. The main purpose of this type of tutoring program is to monitor the teaching of these students in relation to their progress and permanence in their studies.

This Unit also coordinates efforts with other internal areas of the university, such as admission and enrolment, dining halls and residences, national and international mobility services, and employment services, among others.

The annual budget investment is around 20.000 euros although handicapped students benefit from most of the specific services for all the students. Also, the Unit signs agreements with NGOs and voluntary organizations.

\section{Accessibility Plans}

Accessibility refers to guaranteeing that different activities can be carried out by any student without being hindered by any type of barrier.

The URJC monitors continuously the accessibility to facilities and infrastructures, including the study of architectural barriers and the campuses physical conditions. Several marked parking spaces are reserved at each Campus for members of the university community with disabilities. The University's catering services area also adapted to accommodate people with disabilities, so that they can access the restaurant and its services.

\section{A PRELIMINARY EVALUATION OF THE PROGRAM: LIMITATIONS AND FUTURE RESEARCH DIRECTIONS}

The present study was designed to evaluate the outcomes of the program for disabled students at the URJC by applying qualitative analysis techniques on the basis of previous literature used as a guide for our work (Taylor, 2004; Brandt, 2011 Beauchamp-Pryor, 2013). We wanted to examine the effectiveness of the program by interviewing a comprehensive sample of handicapped students and university faculty directly involved in lecturing as well as officers and other students. However, we were only capable of interviewing 14 handicapped students (an estimated $25 \%$ of the total) and 20 other students wo regularly interacted with their disabled mates. We found neither a self-evaluation nor an internal diagnosis that may 
allow the identification of strengths and areas of improvement. Also, there are not satisfaction surveys sent to students with disabilities.

Therefore, we had to rely on the personalized interviews, which allowed us to know the individual opinion of disabled students with respect to the design and implementation of the program. Limited by the meagre range of data that was available, mainly obtained from documentary evidence and students' perceptions we found that the objectives of the program do not match with the expectations. In particular, there is no evidence of the implementation of the accessibility plans explicitly mentioned in the internal regulations. There is no financial support for handicapped students through scholarships and grants and the use of the support services budget is not very clear. Also, there is an absence of psycho-educational advice and there are no specific associations to serve as a meeting point for students with similar characteristics, to exchange experiences, to provide support and the like. Besides, there is no presence of disable students in the representative and governing bodies of the University. Finally, the exploratory analysis based on student's perceptions shows that disabled students are not a priority for the university and that they have to make an extra effort in completing their curricula.

All in all, this study is only a preliminary one since we have found difficulties in obtaining specific data regarding the particular characteristics of the university community with disabilities, segmented by different variables (level of studies, branch of knowledge, gender, type and degree of disability, etc.), that have to be crossed. Our findings have to be interpreted cautiously since a more precise measure requires the provision of data regarding the interactions of teaching and research staff, officers and other students with disable students and their perceptions of the program. A more systematic empirical analysis would require taking these data into consideration.

For this reason, our findings of this exploratory study do not reinforce the conclusions of previous studies as it becomes clear that it exists only in design but has not been fully developed or implemented. The mere adoption of disability legislation does not mean its immediate implementation and institutionalization.

Certainly, diversity management should be a priority and a key issue in the social responsibility of universities because, there is no doubt, handicapped university students deserve the best institutional efforts to promote their full inclusion.

\section{REFERENCES}

Beauchamp-Pryor, K. (2013). Disabled Students in Welsh Higher Education: A Framework for Equality and Inclusion. Leiden: Brill.

Brandt, S. (2011). From Policy to Practice in Higher Education: The experiences of disabled students in Norway. International Journal of Disability, Development and Education, 58(2), 107-120.

Fuller, M., Georgeson, J., Healey, M., Hurst, A., Kelly, K., \& Riddell, S. (2009). Improving disabled students' learning: Experiences and outcomes. London: Routledge.

Harvey, J. (2018). Contemporary Social Theory as a Tool to Understand the Experiences of Disabled Students in Higher Education. Social Inclusion, 41(4), 107-115.

Konur, O. (2006). Teaching disabled students in higher education. Teaching in Higher Education, 11(3), $351-363$.

Riddell, S. (2005). Disabled students in higher education. London: Routledge.

Riddell, S., \& Weedon, E. (2014). Disabled students in higher education: Discourses of disability and the negotiation of identity. International Journal of Educational Research, 63, 38-46.

Seale, J.K. (2006). E-learning and disability in higher education: Accessibility research and practice. London: Routledge.

Taylor, M. (2004). Widening participation into higher education for disabled students. Education + Training, 46(1), 40-48. 